\title{
A AULA COMO ESPAÇO DE CONSTRUÇÃO DE SABERES: O ESTÁGIO EM DOCÊNCIA NO ENSINO SUPERIOR
}

\author{
Jucyelle da Silva Sousa ${ }^{1}$ \\ Antonia Dalva França-Carvalho ${ }^{2}$
}

\section{CONSIDERAÇÕES INICIAIS}

O início à docência no Ensino Superior é sempre um grande desafio, principalmente, para os futuros professores que fazem parte de Programas de PósGraduação como o Mestrado, por exemplo, onde muitos desses profissionais não tiveram oportunidades de lecionar no ensino superior para acadêmicos que buscam uma formação para ingressar no mercado de trabalho, como também, para profissionais que iram iniciar um primeiro contato com à docência, através do Estágio.

Nesse contexto o professor no decorrer de sua carreira profissional passa por diferentes momentos, enfrentam problemas, necessidades, questiona-se sobre sua profissão, encara diversos desafios e inúmeros dilemas, construindo a partir disso o seu conhecimento profissional (NONO, 2011). Neste sentido, a aula como espaço de formulação de saberes é um desafio para estes profissionais que se veem como docentes do Ensino Superior, ainda que seja em faze de Estágio, Veiga et al (2007, p. 175) afirma que a aula "é o espaço onde o professor faz o que sabe, expressa o que sente e se posiciona quanto à concepção de sociedade, de homem, de educação, de escola, de aluno e de seu próprio papel". Ou seja, a aula ocorre em um ambiente de relações humanas, é um espaço de formação humana.

Segundo Ibernón (2011, p.28), "ver o docente como um profissional implica dominar uma série de capacidades e habilidades especializadas que o fazem ser

\footnotetext{
${ }^{1}$ Mestre em Educação. Professora da Educação Básica. Pesquisadora do Núcleo Interdisciplinar de Pesquisas em Educação e Epistemologia da Prática Profissional (NIPEEPP). Email: ju-cy13@hotmail.com

${ }^{2}$ Doutora em Educação. Professora do Programa em Pós-Graduação em Educação da UFPI e do Departamento de Fundamentos da Educação, do Centro de Ciências da Educação, da Universidade Federal do Piauí. Presidente da Comissão de Governança dos Programas de Formação Inicial de Professores, da Universidade Federal do Piauí. Líder do Núcleo Interdisciplinar de Pesquisas em Educação e Epistemologia da Prática Profissional (NIPEEPP). E-mail: adalvac@uol.com.br.
} 
competente em determinado trabalho". Assim, compreendemos que o docente possui habilidades e competências para desenvolver sua aula, interagindo assim, na prática da sua profissão.

Ainda nas concepções de Veiga (2008, p. 8) "[...] a aula é um projeto de construção colaborativa entre professores e alunos. Envolve o pensar a docência e o agir, mas também implica desvelar o novo e enfrentar o imprevisto". É em meio a um conjunto de experiências e interações proporcionadas pela aula, que iremos relatar o dia-a-dia em sala de aula de uma professora em inicio de docência no ensino superior. Diante disso, ao nos reportarmos sobre as vivências das aulas como veículo mediador de aprendizagem, faz-se necessário, compreender qual o significado de aula.

Assim, as experiências mencionadas no decorrer deste artigo ${ }^{3}$ referem-se às aulas realizadas na disciplina de Fundamentos da Educação Infantil, tendo como professora titular da turma a Professora Doutora em Educação, Antonia Dalva França Carvalho. As vivências nas aulas ocorreram durante o Estágio de Docência, atividade que possibilita Mestrandos e Doutorandos de Programas de PósGraduação ter o contato com atividade docente e, com a realidade do Ensino Superior, permitindo ao docente desenvolver suas próprias competências.

O Estágio de Docência é parte complementar da formação do Pós-graduando, pois, objetiva a sua preparação para a docência, e a qualificação do ensino de graduação sendo obrigatório para todos os bolsistas do Programa de Demanda Social. Conforme a Portaria n. 76, de 14 de abril de 2010, da Coordenação de Aperfeiçoamento de Pessoal de Nível Superior (CAPES) (BRASIL, 2010).

Portanto, esboçamos o objetivo geral do presente trabalho que consiste em descrever as vivências das aulas no Ensino Superior na disciplina Fundamentos da Educação Infantil vividas no Estágio em Docência através do curso de Mestrado em Educação da Universidade Federal do Piauí (UFPI), para a turma do terceiro período noturno (2016/1) do curso de Licenciatura em Pedagogia, bem como, descrever as relações de interação entre professor e aluno.

No intuito de corresponder a estes objetivos recorremos a uma pesquisa narrativa. Que na acepção de Souza (2006), as narrativas como atividade de

\footnotetext{
${ }^{3}$ Este artigo possui sua versão original publicada na obra FRANÇA-CARVALHO, A. D. et al. (org.) Notas de aula: dialogando sobre práticas de aprendizagens na escola e na universidade. Teresina, EDUFPI, 2017.
} 
formação, são marcadas como processo de formação e de conhecimento, pois se respaldam nos recursos das experiências assim como nas marcas acumuladas vividas pelos sujeitos em processo de formação e de desenvolvimento. O lócus de prática das aulas foi à sala de aula do curso de Pedagogia da UFPI, localizada no Centro de Ciências da Educação (CCE/UFPI). Tendo como participantes envolvidos a professora orientadora do Mestrado e titular da turma, a docente iniciante no desenvolvimento do Estágio e 23 acadêmicos. As aulas proporcionaram um ambiente de interação entre alunos e professor o que nos leva ao encontro de Tardif (2014, p. 118) "ao entrar em sala de aula, o professor penetra em um ambiente de trabalho construído de interações humanas". Assim, o dia-a-dia em sala de aula nos revelou que ensinar envolve uma série de relações, onde o ensino se torna um processo de construção compartilhada de significados e de aprendizagens, direcionando ao o êxito de uma aula.

Para delinear o desenvolvimento deste estudo estabelecemos o seguinte desenho. Na introdução iniciamos as primeiras discussões acerca da temática deste estudo, destacando nosso objetivo e o lócus do estudo. Mais a frente, dialogamos sobre nossas vivências e descrevemos algumas de nossas aulas, as metodologias utilizadas e o desenvolvimento de nossa prática. Por fim, relatamos as marcas deixadas pelas práticas da docência durante as aulas.

\section{ESPAÇO DE CONSTRUÇÃO DE SABERES: A AULA}

Ao iniciarmos nossas reflexões, mencionamos ser necessário compreender o significado de aula. Neste sentido partimos do pressuposto que existem duas realidades para a conceituarmos, que segundo Silva (2008) é a sala de aula e a aula, pois, apesar de inseparáveis se constituem em contextos diferentes. A autora destaca que, a "sala de aula e aula têm a princípio a mesma conotação, embora com diferenças expressivas. Sala é o local apropriado para o exercício de alguma função, turma de alunos, compartimento, espaço aberto ao público, e aula é explicação, lição" (Ibidem, p.16). Embora indissociáveis, compreende-se que, são espaços proporcionados para a formulação de saberes, que assume a condição da formação humana.

Para Masetto (2003, p.75) "a aula funciona numa dupla direção: recebe a realidade, trabalha-a cientificamente, e volta a ela de uma forma nova, enriquecida 
com a ciência e com propostas novas de intervenção". Isso ocorre a partir do momento em que professores e alunos se constroem sujeitos da realidade, tanto dentro da sala de aula como no mundo lá fora. O comprometimento com a qualidade do ensinar e do aprender dentro da sala de aula direciona a produção de conhecimentos, permitindo ao aluno agir sobre sua própria realidade (FERNANDEZ, 2008).

Neste contexto Farias et al (2014, p. 166) propõe pensar a aula "como um espaço tempo coletivo de formulação de saberes, lócus de produção de conhecimentos que pressupõe a existência de sujeitos que se relacionam, se comunicam e se comprometem com a ação vivida". Ou seja, o professor precisa proporcionar condições a sua aula mediando aprendizagens, e, possibilitando o desenvolvimento da aprendizagem dos discentes em sala de aula, bem com o comprometimento dos mesmos, permitindo criar em conjunto. Foi com esse intuito que as aulas forma regidas no decorrer da disciplina de Fundamentos da Educação Infantil, permitindo a construção de saberes, priorizando a aprendizagem e o comprometimento do professor-aluno, aluno-professor valorizando a interação entre ambas as partes.

As aulas estabeleceram um ambiente de liberdade e autonomia entre professores e alunos, construídos por meio da reciprocidade. É a forma como professores e alunos se relacionam que configura a aula como um encontro entre eles, o qual promove a aprendizagem (MASETTO, 2013).

Diante disso, mencionamos a seguir, o caminho metodológico na Disciplina de Fundamentos da Educação Infantil, ressaltando a realidade das vivências no interior da sala de aula.

\section{O CAMINHAR EM SALADE AULA}

A disciplina foi ministrada no primeiro semestre de 2016, no 3 p período de Pedagogia no turno da noite, todas as sextas-feiras de 18:00 às 22:00 totalizando uma carga horária de 60 horas, a turma era composta por 23 alunos, sendo alguns do $5^{\circ}$ período, mas sua maioria composta pelo $3^{ }$período.

As aulas iniciaram dia 08 de abril de 2016, onde tivemos o primeiro contato com os alunos, realizamos uma breve apresentação com uma dinâmica no qual os alunos e as professoras se apresentavam. Posteriormente, apresentamos o plano da 
disciplina, e firmamos um contrato pedagógico, onde elencamos como seria o nosso dia a dia em sala de aula com compromisso e responsabilidade. Para Zabala (1998, p. 129) "recebe o nome de contrato porque cada aluno estabelece um acordo com o professor sobre as atividades que deve realizar durante o período". Assim, ao mesmo tempo em que o contrato pedagógico contribui para a conduta e convivência em sala, promove aprendizagem de conteúdos e a autonomia dos alunos.

Posteriormente, em conjunto com a professora orientadora desenvolvemos um plano de conteúdos que foram trabalhados durante toda a disciplina. Organizamos textos para leituras e discussões em sala de aula, onde os assuntos propostos centravam-se às necessidades da disciplina e da turma. Para a leitura e interpretação dos textos, trabalhamos com seminários, leituras em grupo e rodas de conversas, construindo um ambiente de aprendizagem significativo, com interações e trocas de saberes.

Os conteúdos da disciplina foram elaborados em quatro unidades diferentes, porém com conteúdos distintos, explorando diversos teóricos e atividades, possibilitando aos alunos uma melhor compreensão das temáticas abordadas, permitindo uma organização dos conteúdos, denominando as relações e vinculando os diferentes conteúdos de aprendizagem formando, assim, as unidades didáticas, como apresenta Zabala (1998).

Para melhor entendimento da metodologia adotada em nossas aulas, a Tabela 1, logo abaixo, mostram as unidades, os conteúdos trabalhados durante a disciplina e a metodologia. Posteriormente explanaremos algumas das atividades desenvolvidas.

Tabela 1 - Unidades, Conteúdos e metodologia trabalhados na disciplina de Fundamentos da Educação Infantil.

\begin{tabular}{|c|c|c|}
\hline \multirow[b]{2}{*}{ Unidade I } & CONTEÚDOS & \multirow{3}{*}{$\begin{array}{l}\text { METODOLOGIA } \\
\text { Síntese; } \\
\text { Linha do tempo; }\end{array}$} \\
\hline & -Evolução histórica da Educação & \\
\hline $\begin{array}{l}\text { Educação Infantil: aspectos } \\
\text { históricos, político e legais. }\end{array}$ & $\begin{array}{l}\text { Infantil. } \\
\text {-Concepções de infância e de } \\
\text { Educação Infantil. } \\
\text {-Profissionais da Educação Infantil: } \\
\text { formacão e atuacão. }\end{array}$ & \\
\hline $\begin{array}{l}\text { Unidade II } \\
\text { Abordagens Psicológicas do } \\
\text { Desenvolvimento moral e suas } \\
\text { implicações pedagógicas. }\end{array}$ & $\begin{array}{l}\text {-Desenvolvimento moral: as } \\
\text { contribuições de Freud, Piaget e } \\
\text { Vygotsky. } \\
\text {-Implicações das teorias do }\end{array}$ & $\begin{array}{l}\text { Aula expositiva com auxilio de } \\
\text { Roteiro de estudo. }\end{array}$ \\
\hline
\end{tabular}




\begin{tabular}{|c|c|c|}
\hline & $\begin{array}{l}\text { desenvolvimento moral na prática } \\
\text { pedagógica. }\end{array}$ & \\
\hline $\begin{array}{l}\text { Unidade III } \\
\text { Abordagens Psicológicas do } \\
\text { Brincar e suas implicações } \\
\text { pedagógicas. } \\
\text { Referencial Curricular Nacional } \\
\text { para Educação Infantil. }\end{array}$ & $\begin{array}{l}\text {-Abordagem Psicanalítica do } \\
\text { brincar. } \\
\text {-Abordagem construtivista do } \\
\text { brincar. } \\
\text {-Abordagem histórico-cultural do } \\
\text { brincar. }\end{array}$ & Seminários. \\
\hline $\begin{array}{l}\text { Unidade IV } \\
\text { O desenho na Educação } \\
\text { Infantil. }\end{array}$ & $\begin{array}{l}\text {-O desenho infantil e suas relações } \\
\text { nos processos de desenvolvimento } \\
\text { e aprendizagem. } \\
\text {-Mediação pedagógica e desenho } \\
\text { infantil. }\end{array}$ & $\begin{array}{l}\text { Roda de conversas; Aula } \\
\text { expositiva dialogada; } \\
\text { Portfólio; }\end{array}$ \\
\hline
\end{tabular}

Fonte: Autoras, 2016.

Podemos observar que as unidades foram divididas em conteúdos, sendo trabalhadas através de diferentes metodologias de ensino, como roda de conversa, aula expositiva dialogada, trabalhos e leituras em coletivo e seminários. Nesse sentido Masetto (2003) afirma que a aula deve ser um espaço que permita aos alunos discutir, pesquisar, debater e confrontar opiniões de tudo aquilo que constitui o ser. Apresentamos, a seguir, algumas metodologias que achamos pertinentes serem destacadas.

A inserção no contexto da sala de aula foi gradual desencadeada com a observação e prática das primeiras aulas. É impossível não mencionar o medo e o sentimento de incapacidade ao assumir uma turma de graduação, pois há um choque com a realidade, visto que no meu caso não tinha vivências como docente em um ambiente de Ensino Superior, o que nos leva ao encontro de Farias et al (2014, p. 58):

\footnotetext{
O professor como qualquer outro ser humano, se produz por meio das relações que estabelece com o mundo físico e social. É pela ação interativa com as dimensões materiais e simbólicas da realidade social em que se encontra inserido, pelas experiências individuais e coletivas tecidas no mundo vivido, que o docente intervém de modo criativo e autocriativo em sua relação com os outros e com o universo do trabalho.
}

Entendemos, portanto, que é nesse processo que o professor começa a elaborar sua identidade como profissional. É importante ressaltar, que, a identidade docente se determina ainda como um lugar de conflitos e de lutas, uma vez que é nesse meio que o professor se desenvolve e se reconhece como profissional da educação (FARIAS et al, 2014). 
A professora orientadora se fez presente em todo o processo, uma vez que ela passava a me observar durante todo o período letivo. Os primeiros dias a observála, proporcionou um direcionamento para nortear e fazer entender que o espaço ao qual eu tinha medo, permitindo compreender a importância do papel de um professor orientador.

Após o primeiro contato em sala de aula, iniciamos as discussões dos textos como embasamento teórico, dentre os diversos textos que utilizamos para desenvolvimento da disciplina iremos relatar a atividade realizada no texto "Os primeiros passos da educação infantil no Brasil" e "Novos tópicos da educação infantil", que foi trabalhado durante a unidade I e relatava a evolução da Educação Infantil durante os anos.

Nesta aula tínhamos como objetivo proporcionar a interação da turma entre si. Para isso, solicitamos que se dividissem em dois grupos, ficando cada grupo com um texto. A proposta foi que todos lessem os textos e, em seguida, cada grupo iria discutir um pouco sobre o que abordava cada um, permitindo uma troca de saberes entre os alunos, o interessante que pudemos observar é que além dos alunos participarem da exposição dos textos eles sempre aliavam algo do texto com sua realidade. O que condiz com a fala de Masetto (2003, p. 75) onde os alunos percebem que "as aulas lhes permitem voltar á sua realidade pessoal, social e profissional com "mãos cheias" de dados novos e contribuições significativas, esse espaço e ambiente começa a ser um espaço de vida para eles". Assim, compreendemos que durante nossas regências os alunos se encontravam na disciplina, por esta permitir que estes a relacionassem com seu dia-a-dia.

Ao final da interpretação e exposição de cada grupo em relação aos textos, os alunos deveriam criar uma linha do tempo coletivamente, abordando todo 0 processo histórico que estava sendo retratado em cada texto. Para Masetto (2003, p. 75) o trabalho em equipe,

[...] entre o professor e aluno busca responder às expectativas e necessidades do grupo classe, trocar e discutir experiências, criar um clima de segurança e abertura para críticas e pensamentos divergentes; na medida em que professor e aluno se comprometam a oferecer informações demonstrando a consecução de objetivos ou a necessidade de novas oportunidades a fim de que algo que não tenha sido aprendido possa ser desenvolvido imediatamente e a aprendizagem se efetive. 
Entendemos que ao desenvolvermos uma atividade onde alunos e professores estejam trabalhando em conjunto, teremos um ambiente onde a aula permitirá trocas de saberes entre os colegas sendo um fator altamente favorável à melhoria da aprendizagem, conforme nos mostra as figuras (FIG. 1, 2, 3 e 4).

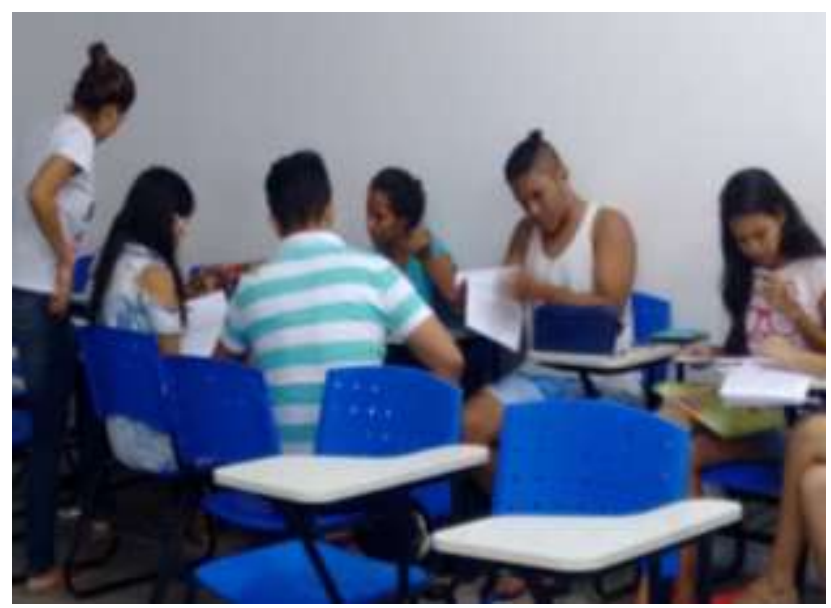

Figura 1 - Construção coletiva da linha do tempo dos primeiros passos da história da Educação Infantil no Brasil. Fonte: Autora, 2016.

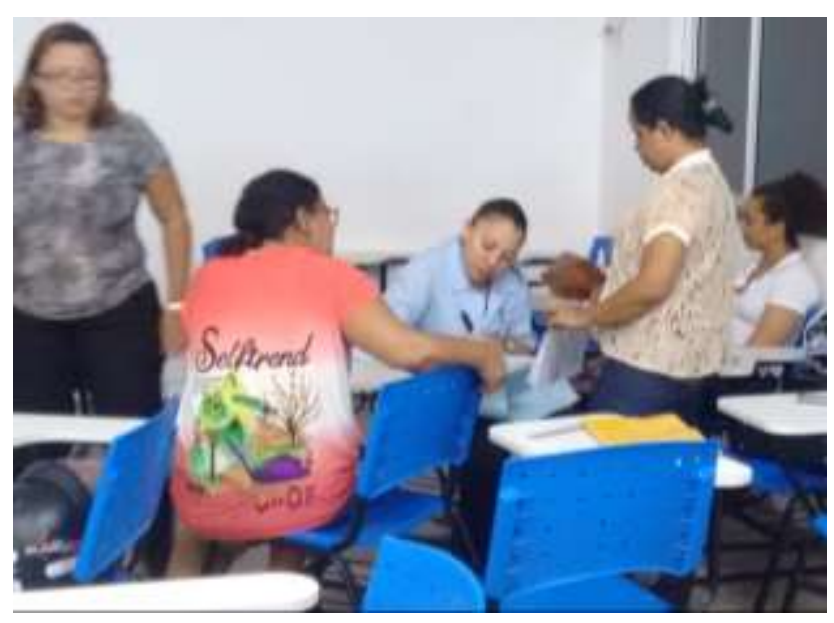

Figura 3 - Construção coletiva da linha do tempo dos novos tópicos na história da Educação Infantil no Brasil. Fonte: Autora, 2016.

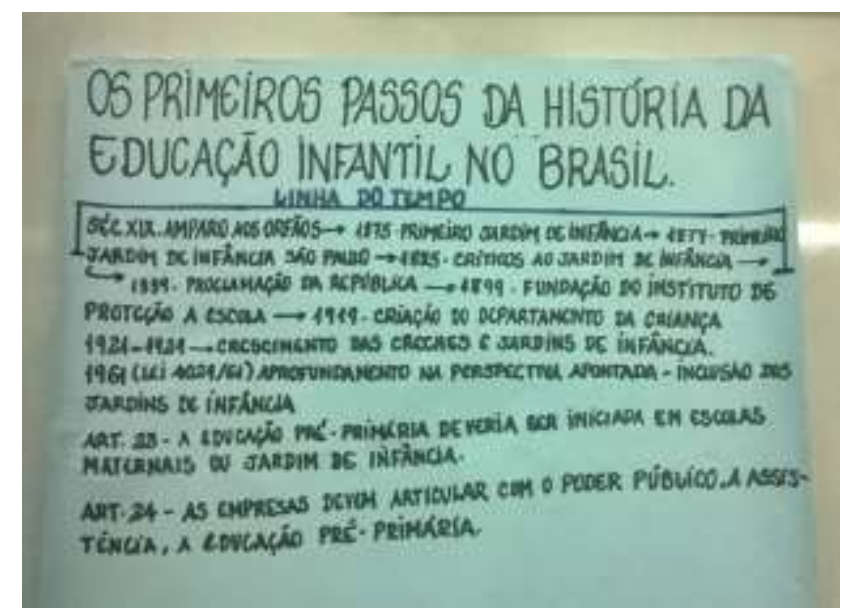

Figura 2 - Linha do tempo os primeiros passos da história da Educação Infantil no Brasil. Fonte: Autora, 2016.

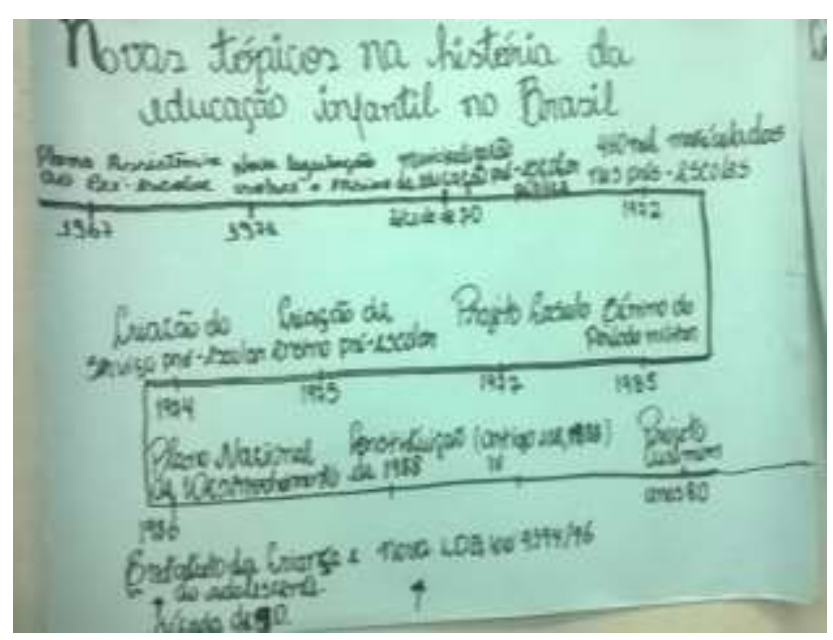

Figura 4 - Linha do tempo novos tópicos na história da Educação Infantil no Brasil. Fonte: Autora, 2016.

As figuras nos permitem compreender que o uso de métodos que integrem 0 grupo, como a construção coletiva da linha do tempo, incentiva a participação dos alunos, permitindo que as aulas se tornem cada vez mais um ambiente de trabalho em equipe. 
Dando continuidade aos relatos de nossas aulas, descrevemos outra proposta de atividade em que trabalhamos com a turma, que foi à apresentação de seminários. É importante ressaltar que inserimos dentro do nosso Plano de Ensino o Referencial Curricular Nacional para a Educação Infantil (RECNEI), pois, é pertinente trabalhar os objetivos, conteúdos e orientações didáticas para os profissionais que atuam diretamente com crianças de zero a seis anos. Uma vez que, a disciplina de Fundamentos da Educação Infantil vem preparar o discente para atuar em sala de aula com alunos da Educação Infantil (BRASIL, 1998).

Diante disso, o RECNEI é uma coleção que integra uma série de documentos dos Parâmetros Curriculares Nacionais (PCN) elaborados pelo Ministério da Educação e do Desporto. Dividido em três volumes o RECNEI trás em seu primeiro volume um documento introdutório, que apresenta uma reflexão sobre creches e pré-escolas no Brasil. Em seu segundo volume discute sobre o âmbito de experiência Formação Pessoal e social e o seu terceiro volume, o qual trabalhamos em sala de aula, contém seis documentos referentes aos eixos de trabalho orientados para a construção das diferentes linguagens pelas crianças e para as relações que estabelecem com os objetos de conhecimento: Movimento, Música, Artes Visuais, Linguagem Oral e Escrita, Natureza e Sociedade e Matemática, (BRASIL, 1998).

Dividimos os seis eixos de trabalhos do RECNEI para a turma, e solicitamos aos alunos que além da apresentação eles deveriam trazer um instrumento pedagógico (atividade, brincadeira, dinâmica, etc.) que condicionasse à interação do grupo com a turma, relacionando a com o tema a ser apresentado. Pois, compreendemos que através das técnicas adotadas em sala por parte do professor pode gerar motivações para aprendizagem e para o envolvimento dos alunos (MASETTO, 2013).

Optamos por trabalhar com seminários em nossas aulas, pois, essa técnica, segundo Farias et al (2013, p. 149):

[...] fomenta a capacidade de pesquisa, análise, interpretação e síntese dos alunos por meio tanto do exercício da oralidade quanto da sistematização escrita de sua reflexão. Fortalece e amplia as formas de interação do aluno com o saber, com seus colegas e com o professor.

Ou seja, estratégias de ensino como essa direcionam de forma significativa os alunos, pois neste tipo de atividade eles socializam os seus pensamentos e 
compreensão das temáticas em questão com os demais alunos. E, o professor pode interagir com a sala, contribuindo para apresentação e para a aprendizagem dos mesmos, podemos verificar nas figuras seguintes. (FIG. 5,6,7 e 8).

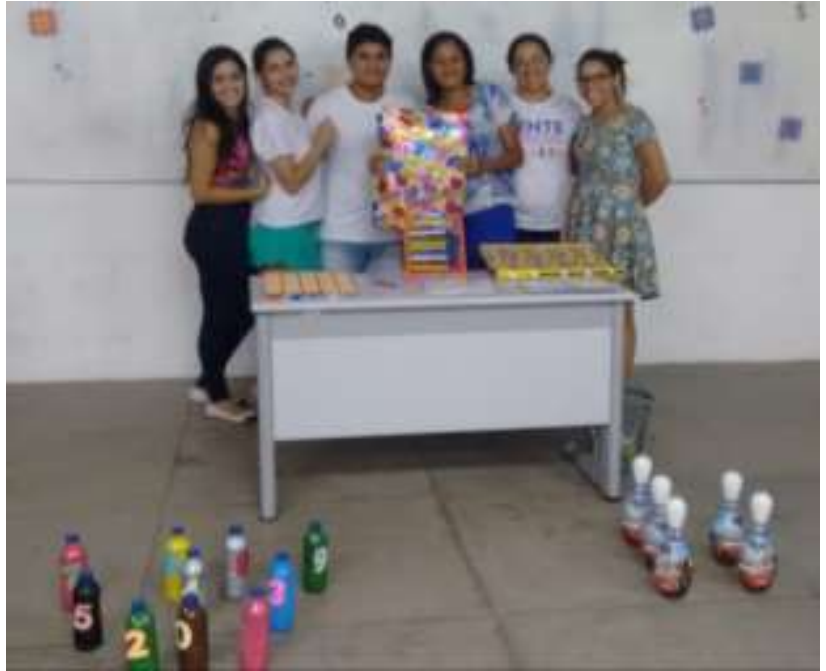

Figura 5 - Apresentação de seminário do eixo de matemática. Fonte: Autora, 2016.

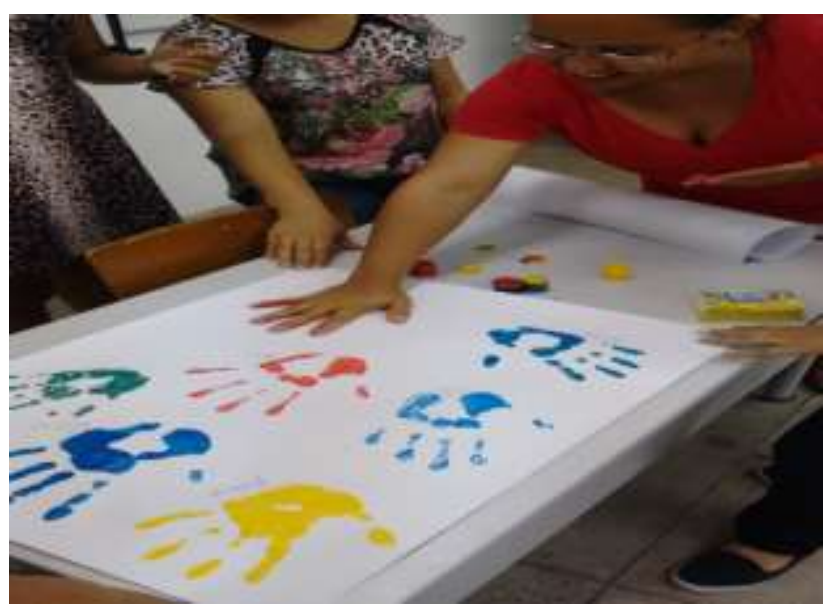

Figura 7 - Apresentação de seminário do eixo de artes visuais. Fonte: Autora, 2016.

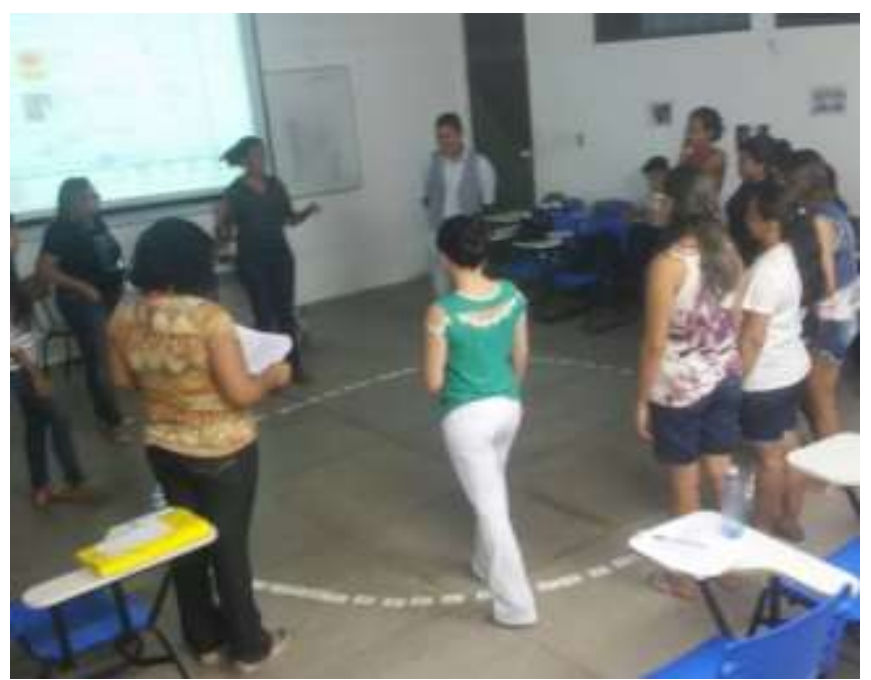

Figura 6 - Apresentação de seminário do eixo de música. Fonte: Autora, 2016.

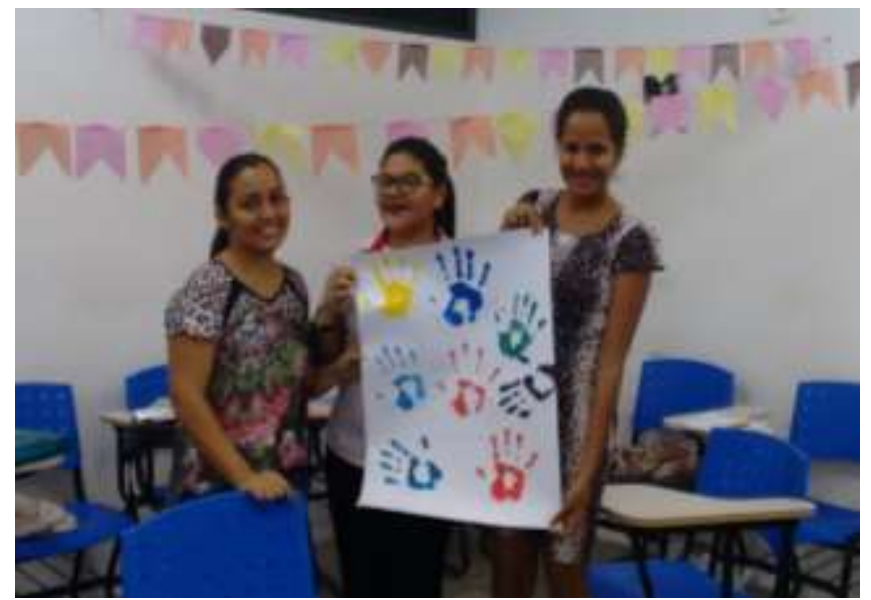

Figura 8 - Apresentação de seminário do eixo de artes visuais. Fonte: Autora, 2016. Fonte: Autora, 2016.

Através das imagens podemos observar que os objetivos propostos para os seminários foram atingidos, uma vez que todos os grupos interagiram com a turma proporcionando um espaço de aprendizagem diferente e diversificado, pois, através das atividades que cada grupo de seminário desenvolvia com a turma, os alunos se mostravam mais participativos e com prazer em participar da aula. 
Por fim, trabalhamos com o uso do Portfólio, no qual adotamos como ferramenta de avaliação final da disciplina. Os alunos registravam todas as atividades desenvolvidas no decorrer da disciplina, escrevendo suas reflexões sobre o seu processo de aprendizagem no portfólio. Para Hernández (2000), o Portfólio é construído através de diferentes formas de documentos, sejam elas notas pessoais, experiências das aulas, representações visuais, trabalhos da disciplina entre outros, proporcionando uma reflexão acerca do conhecimento que foi construído em sala. Assim, compreendemos que este se configura com uma ferramenta avaliativa de grande importância no processo de ensino e aprendizagem.

Segundo Parente (2004, p. 25) adotar o Portfólio como estratégia de avaliação é de extrema relevância, pois se trata de uma avaliação formativa que se fundamenta como um conjunto de:

[...] práticas diversificadas, integradas no processo de ensinoaprendizagem, e que procuram contribuir para que os alunos se apropriem melhor das aprendizagens curriculares através de uma atitude de valorização da participação do aluno em todas as fases do processo educativo. Com este objetivo, os professores tentam construir muitas oportunidades, ao longo do ano, para alunos e professores apreciarem o trabalho realizado e utilizarem a informação que vai sendo obtida para introduzir mudanças no processo de ensino e aprendizagem.

Portanto, compreendemos que o uso do Portfólio como atividade avaliativa vai além de uma coleção de produções, é uma estratégia de ensino que propicia processos de aprendizagens significativos, estimulando de forma expressiva à criatividade dos discentes (FIG. 9).

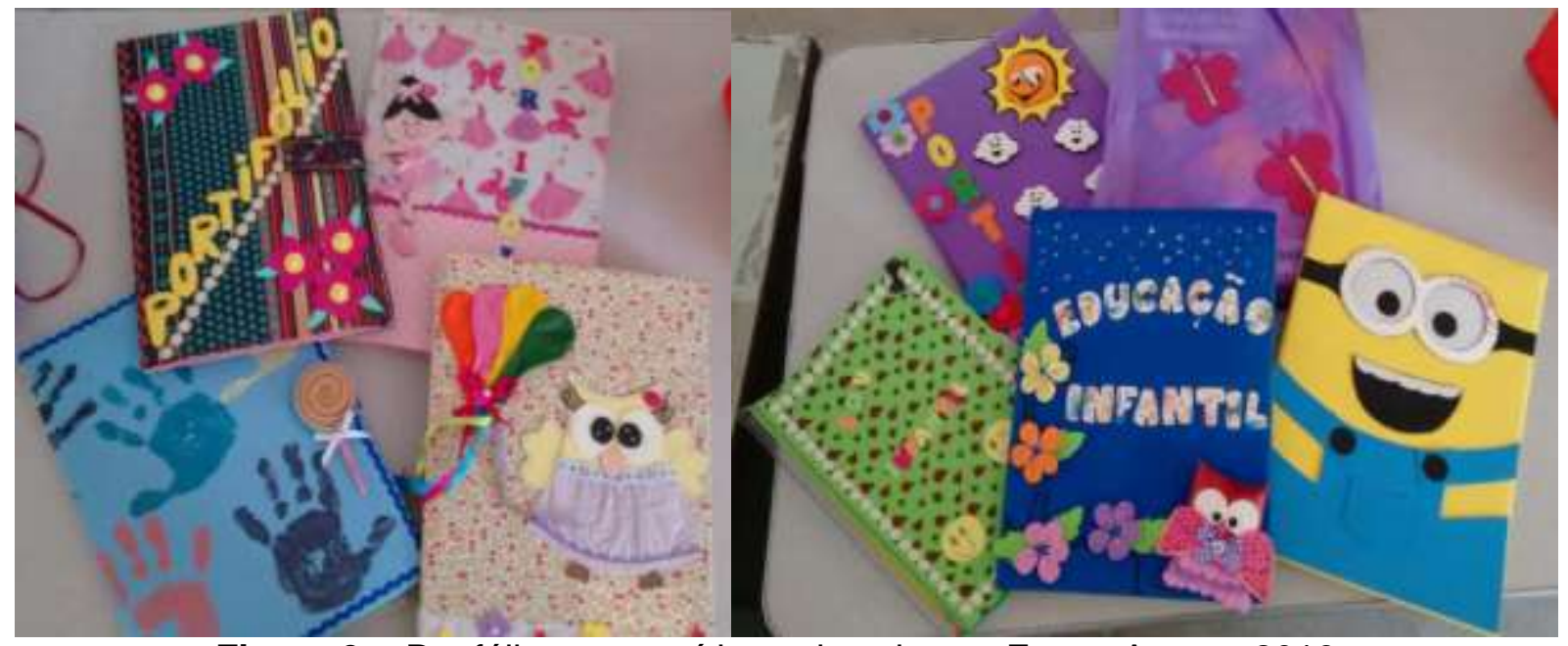

Figura 9 - Portfólios construídos pelos alunos. Fonte: Autora, 2016 
Segundo Martínez (2008, p. 131) é necessário "considerar os processos de criatividade associados aos alunos como membros ativos desse espaço social, incluindo tudo o que está relacionado com sua expressão criativa no processo de aprendizagem". Foi nesse intuito que os alunos elaboraram e construíram seus portfólios, registrando com criatividade os conteúdos e atividades trabalhadas em sala de aula ao longo da disciplina, como também, expondo os seus aprendizados.

A seguir, trazemos as marcas deixadas nas vivências das aulas na visão dos alunos e da professora Estagiária.

\section{AS MARCAS DEIXADAS DAS VIVÊNCIAS DAS AULAS}

No início da disciplina realizamos uma avaliação de diagnóstico, onde buscamos compreender os anseios dos alunos, sobre a Educação Infantil e o que esperavam aprender no decorrer das aulas. A maioria da turma possuía uma noção de Educação Infantil baseada nos saberes experiências e que tinham grandes expectativas para as aulas.

Ao final da disciplina realizamos a mesma avaliação, onde analisamos o que os alunos compreenderam do que foi visto e discutido durante todo o semestre, e, se as expectativas deles foram alcançadas em relação a conteúdos, disciplina e atividades. Com isso, observamos nas falas de alguns alunos o quanto significativo e enriquecedora foi à disciplina de Fundamentos da Educação Infantil.

[...] a disciplina mostrou como a educação é importante para as crianças, como o professor deve aplicar uma aula diferente, dinâmica sem interferir no processo de aprendizagem, muito pelo contrário, a dinâmica em aula como foi visto durante a disciplina é de extrema importância para a aprendizagem. (ALUNO S)

[...] a disciplina me ensinou bastante, me deu um norte e me fez entender o verdadeiro sentido de educar. (ALUNO J)

[...] aprendi a ver a educação infantil com outros olhos, e o quanto é importante o papel do professor que atua nessa área. As minhas expectativas foram além do que eu esperava da disciplina. (ALUNO M)

[...] minhas expectativas foram muitas e foram atendidas, pois por intermédio da disciplina pude ver desde as primeiras concepções de criança e infância, passando por vários teóricos como Vygotsky, Piaget, Freud. Aprendi sobre a formação do docente atuante na educação infantil, as concepções teóricas a respeito do brincar e suas consequências positivas para aquisição da aprendizagem pela criança. A disciplina foi maravilhosa, aprendi muita coisa que irei levar a minha prática docente. (ALUNO R) 
O relato dos discentes na avaliação final foi impactante e surpreendente para mim enquanto professora iniciante do Ensino Superior, uma vez que o medo de não ser capaz, da rejeição por parte dos alunos e a ansiedade fizeram-se presente no inicio dessa caminhada. O que nos leva ao encontro de Shor e Freire (1986, p. 39):

[...] sentir medo é normal, sentir medo é uma manifestação de que estamos vivos. Não tenho que esconder meus temores. Mas, o que não posso permitir é que meu medo seja injustificado, e que me imobilize. (...), entretanto, devo estabelecer os limites para "cultivar" o meu medo. Cultiválo significa aceitá-la.

Ou seja, devemos aceitar nossos medos e não negá-los, pois, só assim você conseguirá por em prática aquilo que tanto sonha. O medo surge dos seus sonhos, e se você negar o medo consequentemente estará negando seus sonhos.

Diante disso, a aula no Ensino Superior, enquanto espaço de formulação de saberes, proporcionou um sentimento de estar aprendendo a ser professora, pois, conforme Nóvoa (2011, p.6):

Formar um professor é possível? Formar não, formar-se! O professor forma a si mesmo através das suas inúmeras interações, não apenas com o conhecimento e as teorias e as teorias aprendidas nas escolas, mas com a prática didática de todos os seus antigos mestres, e outras pessoas, coisas e situações com as quais interagiu em situações de ensino durante toda sua vida.

Neste sentido, constatamos que as experiências vivenciadas na disciplina de Fundamentos da Educação Infantil contribuíram efetivamente para a formação docente, permitindo refletir sobre elas, uma vez que, a reflexão a partir da prática é essencial ao processo de formação.

A proposta do estágio, oferecido pelo Programa de Pós-Graduação da UFPI, é uma oportunidade que vivenciamos, e que, colabora efetivamente para a formação docente de professores que nunca tiveram contato com a regência no ensino superior. Compreendemos que a formação no Ensino Superior não é satisfatória para preparar um docente para desempenhar a sua profissão, pois esta é uma construção que se faz na prática e na reflexão sobre a prática.

As experiências vivenciadas aqui relatadas foram de extrema relevância, pois os resultados da disciplina foram alcançados no decorrer do semestre, o amadurecimento profissional e a interação entre professores e alunos permitiram produzir múltiplos saberes, uma vez que, os saberes são elementos constitutivos da 
prática docente (TARDIF, 2014). Ou seja, o dia-a-dia em sala de aula e as inúmeras trocas de conhecimento direcionam a um novo contexto de aprendizagem, devendo levar em conta os saberes que os alunos possuem para ser possível enriquecê-los.

O processo de construção das aulas como espaço de formulação de saberes, permitiu compreender que estas se constituem como um ambiente de construção colaborativa entre professores e alunos. Pois, envolve o pensar a docência e o atuar, bem como, implica em desvelar o novo e encarar o inesperado (VEIGA, 2008). Assim, uma prática bem elaborada exige correr riscos, mas também, aceitar o novo e buscar uma docência pautada na racionalidade prática, a fim de refletir e lidar com a realidade apresentada nas salas.

Contudo, concluímos que a aula no Estágio de Docência, oportunizou a construção de muitos saberes no decorrer da disciplina de Fundamentos da Educação Infantil, gerando uma articulação simultânea de diferentes saberes. Para tanto, as experiências vividas nas aulas colaboraram para o crescimento profissional enquanto professora de Estágio em Docência e futura docente do ensino superior, uma vez que permitiu reafirmar o interesse pela profissão.

\section{REFERÊNCIAS}

BRASIL. Portaria n. 76, de 14 de abril de 2010. Coordenação de Aperfeiçoamento de Pessoal de Nível Superior - CAPES. Estabelece o novo Regulamento do Programa de Demanda Social constante do Anexo a esta Portaria. 2010. Diário Oficial da União, Seção 1, 19 abr, 2010. Disponível em: <https://www.capes.gov.br/images/stories/download/legislacao/ Portaria_076_RegulamentoDS.pdf >. Acesso em: 02 ago. 2017.

Fundamental. Ministério da Educação e do Desporto. Secretaria de Educação

Referencial Curricular Nacional para a Educação Infantil. Brasília: MEC/SEF, 1998. Disponível em: < http://portal.mec.gov.br/seb/arquivos/pdf/volume3.pdf>. Acesso em: 02 ago. 2017.

FARIAS, I. M. S de; SALES, J. de O. C.B.; BRAGA, M. M. S. de C.; FRANÇA, M do S. L. M. Didática e Docência: aprendendo a profissão. 4. ed. Brasília: Liber Livro, 2014. (Coleção Formar).

FERNANDEZ, A. A inteligência aprisionada. Abordagem psicopedagógica clínica da criança e sua família. Porto Alegre: Artes Médicas, 2008.

HERNÁNDEZ, F. Cultura visual, mudança educativa e projeto de trabalho. Porto Alegre: Artmed, 2000. 
IBERNÓN, F. Formação docente e profissional: formar-se a mudança e a incerteza. 9. ed. São Paulo: Cortez, 2011.

MARTÍNEZ, A. M. A criatividade como principio funcional da aula: limites e possibilidades. In: VEIGA, I. P. A. Aula: gênese, dimensões, princípios e prática. Campinas, São Paulo: Papirus, 2008. p.115-144

MASETTO, M. T. Aula: ambiente de aprendizagem e de trabalho profissional do docente. In: Paulo: Summus, 2003. p.73-83. Competência pedagógica do professor universitário. São

NÓVOA, A. Profissão docente. Entrevista concedida a Paulo de Camargo. São Paulo: Revista Educação, 2011. Disponível em: < http://revistaeducacao.uol.com. br/textos/154/artigo234711-1.asp>. Acesso em: 16 ago. 2017.

NONO, M. A. Professores iniciantes: o papel da escola em sua formação. Porto alegre: Mediação, 2011.

PARENTE, M. C. C. A construção de práticas alternativas de avaliação na pedagogia da infância: sete jornadas de aprendizagem. Tese de Doutorado. Braga, Portugal: Universidade do Minho, 2004. Disponível em: <http://repositorium.sdum.uminho.pt/bitstream /1822/888/1/TESE_CD_IEC_UM.pdf>. Acesso em: 02 ago. 2017.

SHOR, I.; FREIRE, P. Medo e ousadia: o cotidiano do professor. Rio de Janeiro: Paz e Terra, 1986.

SOUZA, E. C. de. O conhecimento de ti: estágio e narrativas de formação de professores. Rio de Janeiro: DP\&A, 2006.

SOUSA, J. da S.; FRANÇA-CARVALHO, A. D. A aula como espaço de construção de saberes: o estágio em docência no ensino superior. In: FRANÇA-CARVALHO, A. D. et al. (org.) Notas de aula: dialogando sobre práticas de aprendizagens na escola e na universidade. Teresina, EDUFPI, 2017. p.76-97.

TARDIF, M. Saberes docentes e formação profissional. Petrópolis, RJ: Vozes, 2014.

VEIGA, I. P. A.; RESENDE, L. M. G.; FONSECA, M. A aula universitária e inovação. In: VEIGA, I. P. A.; CASTANHO, M. E. L. Pedagogia universitária: a aula em foco. 5. ed. Campinas: Papirus, 2007. p.161-192.

VEIGA, I. P. A. Aula: gênese, dimensões, princípios e prática. Campinas, São Paulo: Papirus, 2008.

ZABALA, A. A prática educativa: como ensinar. Porto alegre: Artmed, 1998. 